\title{
Suicide in Alcohol Dependence : clinical and social correlates
}

\author{
Rakesh Kumar \\ Sagar Karia ${ }^{2}$ \\ CRJ Khess ${ }^{3}$ \\ ${ }^{1}$ Senior Resident Doctor, Indira Gandhi Institute of Medical Sciences, Patna. \\ ${ }^{2}$ Specialty Medical Officer - Psychiatry, Department of Psychiatry, Lokmanya Tilak Municipal \\ Medical College, Mumbai \\ ${ }^{3}$ Professor, Department of Psychiatry, Central Institute of Psychiatry, Ranchi. \\ E-mail-drrk2k1@gmail.com
}

\section{ABSTRACT}

Alcohol dependent patients are known to exhibit suicidal ideation and attempt suicide from time to time. The aim of the present research was to study the prevalence of suicidal ideation on person suffering from alcohol dependence and to compare the socio-demographic and clinical variables in patients with alcohol dependence with and without suicidality. 51 male in-patients who gave consent were included and their socio-demographic details were recorded. Following scales were applied: Addiction Severity Index (ASI), Adult Suicidal Ideation Questionnaire (ASIQ), Hamilton Depression Rating Scale (HAM-D), Hamilton Anxiety Rating Scale (HAM-A). They were taken on third or fourth day of admission and again on the $10^{\text {th }}$ day of admission. 8 out of 51 patients had suicidal ideations. Prevalence of anxiety and depression were $74.5 \%$ and $39.2 \%$ on admission and reduced to $52.9 \%$ and $17.2 \%$ on $10^{\text {th }}$ day of admission. There was positive correlation between anxiety and depression with suicidal ideation and less suicidality with longer duration of marriage. Thus there is higher prevalence of suicidality among alcohol dependence patients and it has relation with depression and anxiety symptoms. So need to look for them and treat them to prevent suicidal behaviors in alcohol dependent patients.

Keywords: alcohol, suicide, anxiety, depression.

\section{INTRODUCTION}

The association of alcohol dependence with suicidal behavior is well established although complex. Alcohol consumption and suicide each have a major impact on society. Approximately two third of 18 years of age and older in United States have a lifetime history of drinking alcohol, and an estimated $7.4 \%$ have current alcohol abuse and or dependence [1]. Suicide is generally a complication of a psychiatric disorder but it requires additional risk factors like alcohol and/or substance abuse, marital isolation, not living with a child under age 18 , family history of suicide, parental 
loss before age 11, childhood history of physical and/or sexual abuse, tobacco, smoking, cluster B personality disorders, hopelessness, impulsiveness, aggression, low selfesteem, low cerebrospinal fluid (CSF) 5-hydroxyindolacetic acid (5-HIAA) levels, low blood cholesterol levels, and physical illness because most psychiatric patients never attempt suicide [2]. Suicide attempters and completers have more severe alcoholism compared with individuals with alcoholism but without a history of suicidal behavior. Suicidal individuals show heavier drinking pattern, more alcohol related medical problem, younger age of onset of alcohol misuse, and longer duration of alcoholism [3].

Hence, this study was undertaken to study the prevalence of suicidal ideation on person suffering from alcohol dependence and to compare the sociodemographic and clinical variables in patients with alcohol dependence with and without suicidality.

\section{METHODOLOGY}

This was a cross-sectional study conducted among inpatients of the Center for Addition Psychiatry, Centre Institute of Psychiatry, Ranchi. Male patients of age 18-65 years diagnosed as having alcohol dependence as per Diagnostic Criteria for Research of ICD-10 and those willing to participate were included. Those with other substance use and with other significant co-morbid medical illness were excluded. Demographic details were collected in semi-structured proforma and following scales were used: Addiction Severity Index (ASI), Adult Suicidal Ideation Questionnaire (ASIQ), Hamilton Depression Rating Scale (HAM-D), Hamilton Anxiety Rating Scale (HAM-A). They were taken on third or fourth day of admission and again on the $10^{\text {th }}$ day of admission [4-7].

\section{Addiction Severity Index (ASI)}

ASI is semi-structured interview designed to provide important information about aspect of patient life, which may contribute to his or her substance abuse syndrome. It is the first step in the development of patient profile for subsequent use by research and clinical staff. There were many valid and reliable self-administered instruments appropriate for substance abuse population. But those are usually much focused instrument that has achieved validity and consistency by asking numerous questions related to single theme (e.g. Depression, alcohol use, etc.). But ASI is purposely focused for the purpose outlined above. But there is no viable self administered instrument that can efficiently collect the range of information collected by ASI.

\section{Adult Suicidal Ideation Questionnaire (ASIQ)}

It has 25 items. Each item score ranges from 0-6. Thus total score ranges from $0-150$. It is measure of suicidal ideation and is not intended to identify individuals who are going to attempt suicidal. It measures prevalence of suicidal ideation. Internal consistency and test-retest reliability coefficients range from 0.96-0.97 and $0.85-95$, respectively, in various samples.

\section{Hamilton Anxiety Rating Scale (HAM-A)}


The HAM-A was one of the first rating scales developed to measure the severity of anxiety symptoms, and is still widely used today in both clinical and research settings. The scale consists of 14 items, each defined by a series of symptoms, and measures both psychic anxiety (mental agitation and psychological distress) and somatic anxiety (physical complaints related to anxiety). Each item is scored on a scale of 0 (not present) to 4 (severe), with a total score range of $0-56$, where $<17$ indicates mild severity, 18-24 mild to moderate severity and 25-30 moderate to severe.

\section{Hamilton Depression Rating Scale (HAM-D)}

This is one of the earliest scales to be developed for depression, and is a clinician rated scale aimed at assessing depression severity among patients. The original HAM-D included 21 items, but Hamilton pointed out that the last four items (diurnal variation, depersonalization/derealization, paranoid symptoms, and obsessive compulsive symptoms) should not be counted toward the total score because these symptoms are either uncommon or do not reflect depression severity. Therefore, the 17item version of the HAM-D has become the standard for clinical trials and, over the years, the most widely used scale for controlled clinical trials in depression. The total score is obtained by summing the score of each item, 0-4 (symptom is absent, mild, moderate, or severe) or 0-2 (absent, slight or trivial, clearly present). For the 17-item version, scores can range from 0 to 54. It is accepted by most clinicians that scores between 0 and 6 do not indicate the presence of depression, scores between 7 and 17 indicate mild depression, scores between 18 and 24 indicate moderate depression, and scores over 24 indicate severe depression. A total HAM-D score of 7 or less after treatment is for most raters a typical indicator of remission. A decrease of $50 \%$ or more from baseline during the course of the treatment is considered indicator of clinical response, or in other words, a clinically significant change.

\section{Statistical Analysis}

Data analysis was done by computer software and score of $p \leq 0.05$ was considered as statistically significant.

\section{RESULTS}

The sample consisted of 51 patients of alcohol dependence syndrome diagnosed as per criteria of ICD-10. The mean age of the patients was $35.3 \pm 8.10$. Mean monthly income of the patients is rupees 13554 . While mean money spent on alcohol monthly was 1849.02 rupees. Mean duration of use was $11.76 \pm 5.71$ years. $60.8 \%$ patients were Hindu, $29.4 \%$ were Christian and $9.8 \%$ were Muslim. $78.4 \%$ were married and $19.6 \%$ were unmarried. $19.6 \%$ had family member of alcohol problem living together. Of the total sample 8 patients (15.7\%) were found to have suicidal ideation.

Table 1 compares various socio-demographic and clinical variables amongst those with and without suicidal ideation. It shows very significant correlation between suicidal ideation and anxiety $(p=0.008)$ and Depression $(P=0.000)$. It shows some trend that longer the duration of marriage less suicidal ideation. As per table 2 prevalence of anxiety was $74.5 \%$ when patient got admitted but the prevalence came down $52.9 \%$ on the $10^{\text {th }}$ day of admission. Prevalence of depression was $39.2 \%$ when patient got admitted but the prevalence came down to $17.6 \%$ on the $10^{\text {th }}$ day of admission. Table 3 shows that $87.5 \%$ person with suicidal ideation had anxiety which 
persisted even on second rating on $10^{\text {th }}$ day. Although $72.1 \%$ of patients without suicidal ideation had anxiety, it came down to $46.5 \%$ on second rating on $10^{\text {th }}$ day. $87.5 \%$ of patient with suicidal ideation had depression, which became $75.0 \%$ on second rating on $10^{\text {th }}$ day. Although $30.2 \%$ of persons without suicidal ideation had depression it came down to $7.0 \%$. There was significant correlation $(p=0.002)$ has been found between prevalence of depression and suicidal ideation. Though trend $(p=0.053)$ has been seen between prevalence of anxiety and prevalence of suicidal ideation on $2^{\text {nd }}$ rating.

Table 1: Comparison of Socio-Demographic and Clinical Variable in those with or without suicidal ideation

\begin{tabular}{|c|c|c|c|c|c|c|}
\hline Variable & $\begin{array}{l}\text { suicidal } \\
\text { absent }\end{array}$ & ideation & $\begin{array}{l}\text { suicidal } \\
\text { present }\end{array}$ & ideation & $\mathbf{F}$ & $\mathbf{P}$ \\
\hline & Mean & SD & Mean & SD & & \\
\hline Age of Patient & 35.60 & 7.22 & 35.13 & 12.46 & 6.477 & 0.92 \\
\hline $\begin{array}{l}\text { Duration of Alcohol } \\
\text { use }\end{array}$ & 12.46 & 5.57 & 10.13 & 6.58 & 0.583 & 0.38 \\
\hline $\begin{array}{l}\text { Education } \\
\text { Completed }\end{array}$ & 13.7674 & 10.43 & 10.37 & 3.11 & 0.501 & 0.37 \\
\hline Income monthly & 14659.52 & 30099 & 7750.00 & 3854.50 & 1.716 & 0.52 \\
\hline $\begin{array}{ll}\text { Duration } & \text { of } \\
\text { Marriage } & \end{array}$ & 12.72 & 3.90 & 7.1250 & 9.41 & 0.703 & 0.09 \\
\hline $\begin{array}{l}\text { Hamilton Anxiety } \\
\text { Rating Scale at } \\
\text { Baseline }\end{array}$ & 5.65 & 3.18 & 13.00 & 8.11 & 0.122 & 0.008 \\
\hline $\begin{array}{l}\text { Hamilton } \\
\text { Depression Rating } \\
\text { Scale at Baseline }\end{array}$ & 6.77 & $\begin{array}{l}6.72 \\
6.98\end{array}$ & 19.00 & 7.67 & 0.032 & 0.000 \\
\hline $\begin{array}{l}\text { Adult suicide } \\
\text { ideation } \\
\text { Questionnaire at } \\
\text { Baseline }\end{array}$ & 4.49 & 7.49 & 71.39 & 28.16 & 24.816 & 0.000 \\
\hline $\begin{array}{l}\text { Hamilton Anxiety } \\
\text { Rating Scale at } 10^{\text {th }} \\
\text { day }\end{array}$ & 2.02 & 3.77 & 6.88 & 6.65 & 9.885 & 0.079 \\
\hline $\begin{array}{l}\text { Hamilton } \\
\text { Depression Rating } \\
\text { Scale at } \mathbf{1 0}^{\text {th }} \text { day }\end{array}$ & 2.90 & 3.50 & 11.75 & 4.90 & 0.738 & 0.000 \\
\hline $\begin{array}{l}\text { Adult suicide } \\
\text { ideation } \\
\text { Questionnaire } 10^{\text {th }} \\
\text { day }\end{array}$ & 4.41 & 7.51 & 68.25 & 27.92 & 28.928 & 0.000 \\
\hline
\end{tabular}


Table 2: Prevalence of anxiety and depression in alcohol dependence

\begin{tabular}{|c|c|c|c|c|c|c|c|c|c|c|}
\hline \multirow[t]{2}{*}{ Variable } & \multicolumn{2}{|c|}{ No. } & \multicolumn{2}{|c|}{ Mild } & \multicolumn{2}{|c|}{$\begin{array}{l}\text { Mild to } \\
\text { Moderate }\end{array}$} & \multicolumn{2}{|c|}{$\begin{array}{l}\text { Moderate } \\
\text { to Severe }\end{array}$} & \multicolumn{2}{|c|}{ Total } \\
\hline & $\mathbf{n}$ & $\%$ & $\mathbf{n}$ & $\%$ & $\mathbf{n}$ & $\%$ & $\mathbf{n}$ & $\%$ & $\mathbf{n}$ & $\%$ \\
\hline Anxiety - 1 & 13 & 25.5 & 32 & 62.7 & 4 & 7.8 & 2 & 3.9 & 38 & 74.5 \\
\hline Anxiety -2 & 24 & 47.1 & 27 & 52.9 & 0 & 0 & 0 & 0 & 27 & 52.9 \\
\hline Depression-1 & 31 & 60.8 & 7 & 13.7 & 4 & 7.8 & 9 & 7.6 & 20 & 39.2 \\
\hline Depression-2 & 42 & 82.4 & 6 & 11.8 & 2 & 3.9 & 1 & 2.0 & 9 & 17.6 \\
\hline
\end{tabular}

Table 3: Comparison of Prevalence of anxiety and depression in those with or without suicidal ideation

\begin{tabular}{|cccccccc|}
\hline Variable & \multicolumn{2}{c}{ Suicidal Ideation $\mathbf{t}$} & \multicolumn{2}{c|}{ Suicidal Ideation - } & $\boldsymbol{x}^{\mathbf{2}}$ & $\mathbf{P}$ \\
& $\mathbf{n}$ & $\mathbf{\%}$ & $\mathbf{n}$ & $\mathbf{\%}$ & & \\
\hline Anxiety - 1 & 7 & 87.5 & 31 & 72.1 & 2.67 & 0.442 \\
\hline Anxiety - 2 & 7 & 87.5 & 20 & 46.5 & 4.55 & 0.053 \\
\hline Depression-1 & 7 & 87.5 & 13 & 30.2 & 14.73 & $0.002^{*}$ \\
\hline Depression-2 & 6 & 75.0 & 3 & 7.0 & 22.74 & $0.000^{*} *$ \\
\hline
\end{tabular}

\section{DISCUSSION}

Studies have been done on patients who have attempted suicide to know the relationship between alcohol use and suicide attempt. Even postmortem psychological autopsy of completed suicide has been done to know the relationship between suicide and alcohol use along with socio-demographic variables and other clinical variable [8]. But there were few studies done on admitted patients who had alcohol dependent syndrome to know its relationship with suicidal ideation and suicidal tendency. Many studies had been done to know the prevalence of anxiety disorder and depressive disorder seen in alcohol dependent patients [9-10]. In current study we have seen prevalence of suicidal ideation and suicidal tendency in alcohol dependence syndrome patients along with its relationship with socio-demographic variable and other clinical variables. In previous with studies scale for depression and anxiety and suicidal ideation were applied only once. In the current study it was applied twice one on the $3^{\text {rd }}$ or $4^{\text {th }}$ day of admission and again on the $10^{\text {th }}$ day. Only male patients were taken for the study, as there are no female inpatient beds available in the concerned hospital. Moreover because of the stigma associated with admission of female patients attend the out-patients in the hospital.

The prevalence of suicidal ideation was found in $15.7 \%$ of the total sample. This was in agreement with several other studies. This result was comparable to previous studies which found the prevalence of suicidal ideation to be $17.1 \%$ and $13.5 \%$ [11-12]. Our study showed that longer the duration of marriage less suicidal ideation. Much higher suicide rates have been found for divorced and widowed persons than for married persons in all age groups, with age-adjusted rates. High suicidal intent scores in males were additionally associated with being widowed, divorced or separated [13]. 
Though the two groups in the study, i.e. those without suicidal ideation and those with suicidal ideation, were comparable on various socio-demographic and clinical variables, they significantly differed in baseline and follow up rating of depression and second rating of anxiety. Even earlier studies also have shown significant correlation between anxiety and depression in alcohol dependent patients [11]. A study by Sullivan [14] found that alcohol problems were more common in depression than in the general population. In the current study prevalence of depressive symptoms were $39.2 \%$ when patient got admitted but the prevalence came down to $17.6 \%$ on the tenth day of admission. In a study of prevalence of depression in alcohol abuse was found to be $26.4 \%$ [15]. This lowers prevalence because in above mentioned study alcohol abuse patients were taken instead of alcohol dependent patients. This relationship between alcohol dependence and depression has received unequivocal acceptance [16]. Accordingly, previous data has demonstrated a two-fold increase in the lifeline odds of depression among subjects with alcohol dependence [17].

$87.5 \%$ of patient with suicidal ideation had depressive symptoms, which reduced to $75.0 \%$ on second rating on the tenth day. Although $30.2 \%$ of person without suicidal ideation also had depressive symptoms it reduced to $7.0 \%$. This can be understood by the fact that people with suicidal ideation had greater severity of depressive symptoms in comparison with those who did not have suicidal ideation. Alcohol dependence and depression are frequently concomitant, and it is accepted that depression is a consequence, rather than an original psychopathology or a condition secondary to alcohol dependence. Also self-directed aggression in alcohol-dependent subjects increases the risk of suicide in them [11].

Prevalence of anxiety symptoms were $74.5 \%$ when patient got admitted but the prevalence reduced to $52.9 \%$ on the $10^{\text {th }}$ day admission. $87.5 \%$ patient with suicidal ideation had anxiety symptoms, which persisted, even on second rating on $10^{\text {th }}$ day. Whereas $72.1 \%$ of patient without suicidal ideation had anxiety symptoms which reduced to $46.5 \%$ on second rating on tenth day, thus it can be inferred that patients with suicidal ideation have more persistent anxiety symptoms compared to those without suicidal ideation. This corroborates with the conclusion of the other study [11].

This point of view has also been understood from the concept of state and trait anxiety. The anxiety experienced by an individual in a particular context is defined as 'state anxiety', whereas the anxiety as an answer to how an individual feels in general is defined as 'trait anxiety'. These two types of anxiety were evaluated and their relationship to suicide probability was analyzed. It was seen that the relationship between trait anxiety and suicide probability was highly significant, while the relationship between state anxiety and suicide probability was moderate. Further, trait anxiety predicted suicide risk more strongly than state anxiety. A high level of anxiety in alcoholdependent patients is a biological as well as a psychosocial consequence of alcohol misuse. So, anxiety is an entity that gains persistence in the life of the alcoholdependent individual [11].

The study had some limitations. Sample size was modest due to time constraint. In this study only alcohol dependent patients were taken up as study sample. Hence, one has to be careful while generalizing the finding of this study on patients who consume alcohol but are not dependents per the diagnostic criteria and those who are in the community and have not yet been hospitalized. There was no follow-up rating done on the patients after the discharge. 


\section{REFERENCES}

1. Grant FG, Harford TC, et. al. Prevalence of DSM IV Alcohol abuse and dependence, National Longitudinal Alcohol Epidemiological Survey, pp. 51-57. Us Department of Health and Human Service, Washington DC (NIH Publication) No. - 02-4997; 1992.

2. Sher L, Oqendo MA., Mann JJ. Risk of suicide disorders. Clin Neurosci Res 2001;1:337-44.

3. Berglund M. Suicide in alcoholism. A prospective study of 88 suicides: I. The multidimensional diagnosis at first admission. Arch Gen Psychiatry. 1984;41(9):888-91.

4. McLellan AT, Luborsky L, Woody GE, O'Brien CP. An improved diagnostic evaluation instrument for substance abuse patients. The Addiction Severity Index. J Nerv Ment Dis. $1980 ; 168(1): 26-33$.

5. Reynolds WM. Suicidal Ideation Questionnaire: Professional manual. Odessa, FL: Psychological Assessment Resources ; 1988.

6. Hamilton M. The assessment of anxiety states by rating. $\mathrm{Br}$ J Med Psychol 1959;32:50-5.

7. Hamilton M. Development of a rating scale for primary depressive illness. $\mathrm{Br} J \mathrm{Soc}$ Clin Psychol 1967;6(4):278-96.

8. Pompili M, Serafini G, Innamorati M. Suicidal Behavior and Alcohol Abuse. Int J Environ Res Public Health 2010;7(4):1392-1431.

9. Schuckit MA, Hesselbrock V. Alcohol dependence and anxiety disorders: what is the relationship? Am J Psychiatry. 1994;151(12):1723-34.

10. Raimo EB, Schuckit MA. Alcohol dependence and mood disorders. Addict Behav 1998;23(6):933-46.

11. Demirbas H, Celik S, Ilhan IO, Doğan YB. An examination of suicide probability in alcoholic in-patients. Alcohol Alcohol 2003;38(1):67-70.

12. Sher L. Alcoholism and suicidal behavior: a clinical overview. Acta Psychiatr Scand. 2006;113(1):13-22.

13. Harriss L, Hawton K, Zahl D. Value of measuring suicidal intent in the assessment of people attending hospital following self-poisoning or self-injury. $\mathrm{Br}$ J Psychiatry 2005;186:60-6.

14. Sullivan LE, Fiellin DA, O'Connor PG. The prevalence and impact of alcohol problems in major depression: a systematic review. Am J Med 2005;118(4):330-41.

15. Schuckit MA, Tipp JE, Bergman M, Reich W, Hesselbrock VM, Smith TL. Comparison of induced and independent major depressive disorders in 2,945 alcoholics. Am J Psychiatry. 1997I;154(7):948-57.

16. Miller NS, Giannini AJ, Gold MS. Suicide risk associated with drug and alcohol addiction. Cleve Clin J Med 1992;59(5):535-8.

17. Kessler RC, Nelson CB, McGonagle KA, Liu J, Swartz M, Blazer DG. Comorbidity of DSM-III$\mathrm{R}$ major depressive disorder in the general population: results from the US National Comorbidity Survey. Br J Psychiatry 1996;30(Suppl 2):S17-30.

Acknowledgements - Nil

Conflict of Interest - Nil

Funding - Nil. 